\title{
Effect of Ground Motion Directionality on Fragility Characteristics of a Highway Bridge
}

\author{
Swagata Banerjee Basu' ${ }^{1}$ and Masanobu Shinozuka ${ }^{2}$ \\ ${ }^{1}$ Department of Civil and Environmental Engineering, The Pennsylvania State University, University Park, PA 16802, USA \\ ${ }^{2}$ Department of Civil and Environmental Engineering, University of California, Irvine, CA 92697, USA
}

Correspondence should be addressed to Swagata Banerjee Basu, swagata@engr.psu.edu

Received 1 June 2011; Accepted 27 August 2011

Academic Editor: Manolis Papadrakakis

Copyright ( 2011 S. Banerjee Basu and M. Shinozuka. This is an open access article distributed under the Creative Commons Attribution License, which permits unrestricted use, distribution, and reproduction in any medium, provided the original work is properly cited.

\begin{abstract}
It is difficult to incorporate multidimensional effect of the ground motion in the design and response analysis of structures. The motion trajectory in the corresponding multi-dimensional space results in time variant principal axes of the motion and defies any meaningful definition of directionality of the motion. However, it is desirable to consider the directionality of the ground motion in assessing the seismic damageability of bridges which are one of the most vulnerable components of highway transportation systems. This paper presents a practice-oriented procedure in which the structure can be designed to ensure the safety under single or a pair of independent orthogonal ground motions traveling horizontally with an arbitrary direction to structural axis. This procedure uses nonlinear time history analysis and accounts for the effect of directionality in the form of fragility curves. The word directionality used here is different from "directivity" used in seismology to mean a specific characteristic of seismic fault movement.
\end{abstract}

\section{Introduction}

A spatially distributed civil infrastructure system located in a seismically active region is vulnerable to moderate to strong earthquake events. These extreme natural events may cause system interruption over a long period of time and entail substantial costs for postevent repair and restoration. This often results in unacceptable socioeconomic losses and societal disruption. The highway transportation network serving the State of California typically represents such a system. It is then prudent to develop an emergency response strategy for each community served by the system in order to minimize the negative consequences of the extreme earthquake events. For a highway network consisting of a large number of bridges, the initial step toward the development of such an emergency response strategy is to estimate, by means of predictive simulation, the reduction in the traffic flow capability of the network when its bridges are damaged due to regional seismic activity. Such reduction in the traffic flow capability will provide an estimate of network accessibility at distressed conditions. Consequently, the emergency response activities can be designed prior to any earthquake event.

Because of the predictive and probabilistic nature of system performance simulation, bridge damage due to seismic activity must be simulated (i) on the basis of the ground motion intensity (typically, peak ground acceleration (PGA)) obtainable from the attenuation equations using the fundamental seismic source parameters and (ii) by means of nonlinear time history analysis of bridges. A set of scenario earthquakes consistent with the United States Geological Survey (USGS) seismic hazard maps is developed to represent the regional seismicity. Bridge damage under these scenario earthquakes is predicted from predeveloped seismic fragility curves of these bridges. This procedure has been adopted in the prevailing predictive analyses of bridge failure associated with highway transportation networks [15]. In a seismic fragility curve, the damage sustained by a bridge due to seismic events is estimated as a function of PGA. The value read from the curve is equal to the 
probability that the bridge will suffer from the corresponding damage state for that PGA. Such curves are developed analytically and/or empirically (on the basis of past damaging earthquake experience). The fragility curves are different depending on bridge attributes and site soil condition. These curves also depend on the orientation of seismic ground motion with respect to the bridge axis (such as, longitudinal and transverse). In relevant literatures, fragility curves were developed when the seismic motion coincided with the longitudinal and/or the transverse directions of bridges. However, the horizontal components of ground motions can travel from any orientation to a bridge site and depending on that the maximum seismic demand may vary. This can result in a different scenario of bridge seismic damage than that when the same ground motion components are considered along bridge axes.

The present paper expands the method of seismic fragility analysis of bridges by introducing the directionality of earthquake ground motions. It is considered that the horizontal components of seismic motions propagate at arbitrary directions to bridge axes. The complex trajectory (Figure 1) of two ground motion components, say N-S and E-W components, indicates the difficulty involved in identifying the principal directions of these components. Although it is possible to model the ground motion acceleration time history as a $2 \mathrm{D}$ or $3 \mathrm{D}$ vector random process [6], the model results in time-varying principal axis of the process. Under these circumstances, physical parameters that accurately describe structural behavior particularly in nonlinear range are not currently available and require highly sophisticated experimental and analytical studies. However, recognizing the fact that the directionality of the earthquake ground motion may have an important effect on structural response, researchers have paid attention to this issue in seismic performance analysis. Wilson and Button [7] and Wilson et al. [8] proposed a methodology to estimate the maximum structural response under multicomponent earthquake input. They assumed that the input spectra are statistically independent because of the complex nature of three-dimensional wave propagation. Lopez and Torres [9] and Hernandez and Lopez [10] calculated the critical angle of seismic incidence and the maximum structural response under uncorrelated multi-component earthquake spectra. Note that the word "directionality" has a completely different meaning from the word "directivity" used in seismology to mean a specific characteristic of seismic fault movement.

For a particular bridge configuration, the present study also provides the scope of performing a sensitivity study in order to investigate the most conservative angle of incidence of the ground motion. Thus computed angle of seismic incidence can be used to obtain bridge seismic damageability when no information about the ground motion orientation to the bridge axis is available.

\section{Effect of Ground Motion Directionality on Bridge Response}

To investigate the effect of directionality of two horizontal orthogonal components of earthquake ground motion, the

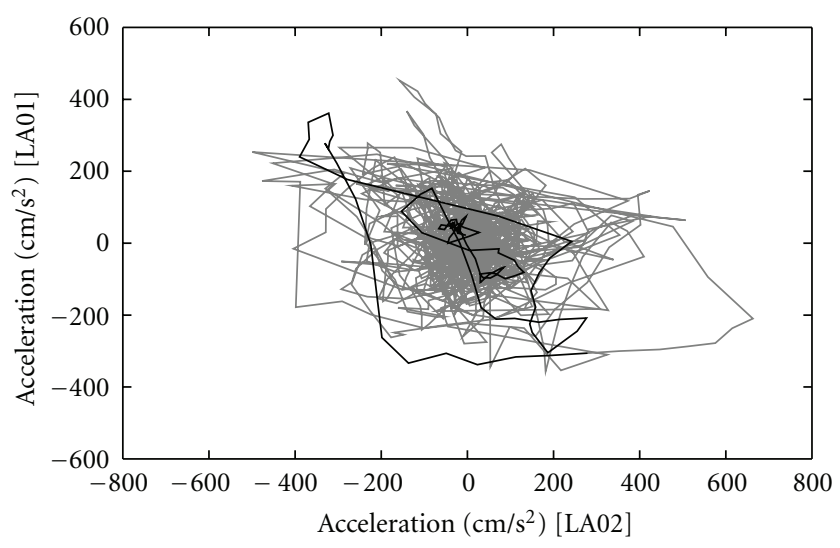

FIGURE 1: Trajectory of ground acceleration time histories observed during the El Centro Earthquake, 1940.

methodology presented in Wilson and Button [7] and Wilson et al. [8] is followed here. It is assumed that one component $G M_{1}$ acts at an angle $\theta$ with respect to the longitudinal $(x)$ axis of a bridge, and, at the same time, the other component $G M_{2}$ acts at an angle of $\left(90^{\circ}+\theta\right)$ with respect to the same axis. Figure 2 schematically shows these motions and relative position of an example bridge. Figure 3 shows the response of the example bridge under $G M_{1}$ and $G M_{2}$ at any time instant $t$. First, $G M_{i}(i=1,2)$ is assumed to act along the longitudinal and transverse directions of the example bridge. Thus, the dynamic response of the bridge at an arbitrary location " $\mathrm{A}$ " and time instant $t$ is measured to be $\left(R_{i j}\right)_{t}$ where $j$ represents the direction ( $x$ for longitudinal and $y$ for transverse direction). This response can either be bridge deformation (such as translational and rotational displacements) or a resultant force (such as moment and force). These response quantities are recorded as functions of time and measured for a constant time increment $(\Delta t)$. Following this, $\left(R_{i j}\right)_{t}$ is projected along the actual directions of $G M_{1}$ and $G M_{2}$ as given in Figure 2. Due to $G M_{1}$, the projections of $\left(R_{1 x}\right)_{t}$ and $\left(R_{1 y}\right)_{t}$ on $\theta$ axis are shown in Figures 3(a) and 3(b). Hence, the resultant response of the bridge at location " $\mathrm{A}$ " and time instant $t$ due to $G M_{1}$ is

$$
\left(R_{1 \theta}\right)_{t}=\left(R_{1 x}\right)_{t} \cos \theta+\left(R_{1 y}\right)_{t} \sin \theta .
$$

Similarly, the response of the bridge under $G M_{2}$ at the same location and time instant can be computed by taking projections of $\left(R_{2 x}\right)_{t}$ and $\left(R_{2 y}\right)_{t}$ on $\left(90^{\circ}+\theta\right)$ axis (Figures $3(\mathrm{c})$ and $3(\mathrm{~d}))$. Hence, this response becomes

$$
\left(R_{2 \theta}\right)_{t}=-\left(R_{2 x}\right)_{t} \sin \theta+\left(R_{2 y}\right)_{t} \cos \theta
$$

These orthogonal ground motion components $\left(G M_{1}\right.$ and $G M_{2}$ ) are assumed to be statistically independent. Obtained bridge responses under these ground motion components include nonlinear range, in general. The use of "square root of sum of square (SRSS)" in the current nonlinear analysis provides an expedient way of deriving resultant response from two response quantities. Thus, the resultant response $\left(R_{\theta}\right)_{t}$ of the bridge at location "A" and any time instant $t$ due 


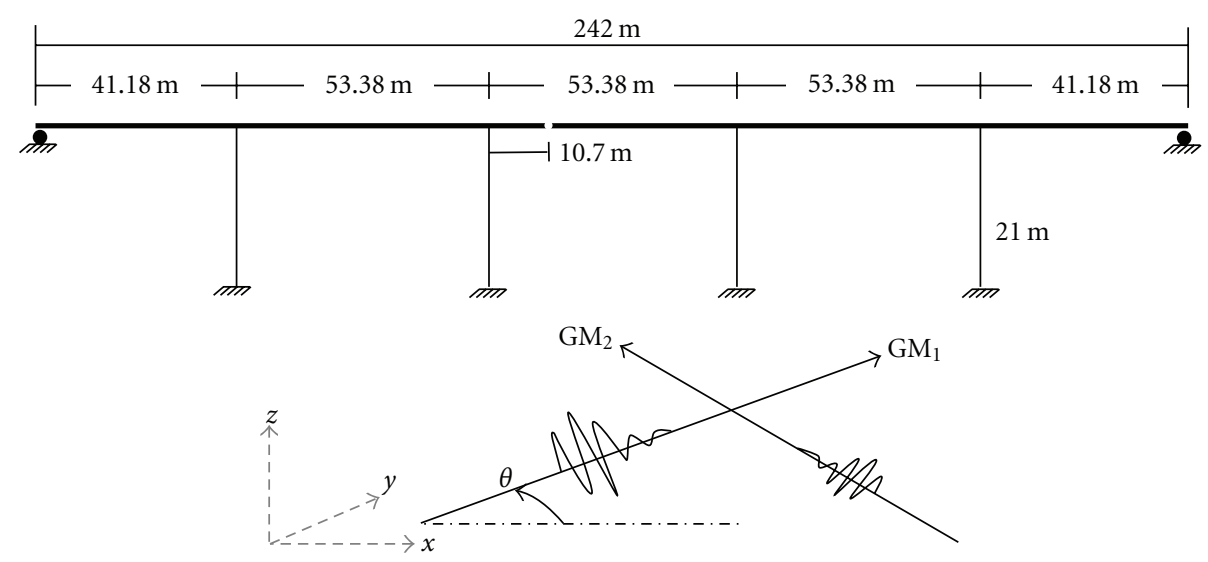

FIGURE 2: Example bridge under two horizontal orthogonal components of earthquake ground motions.

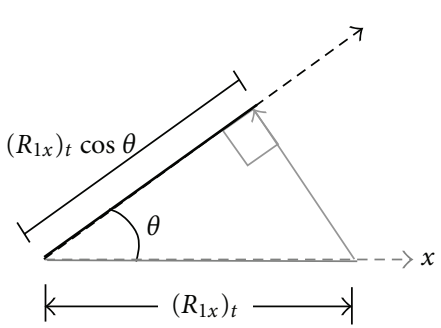

(a)

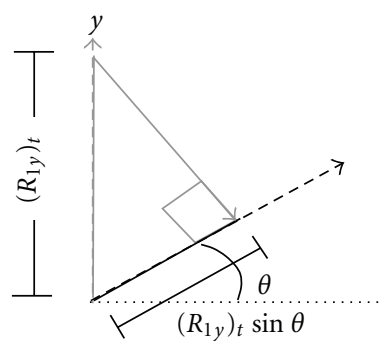

(b)

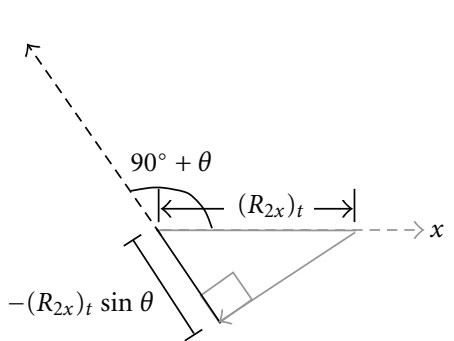

(c)

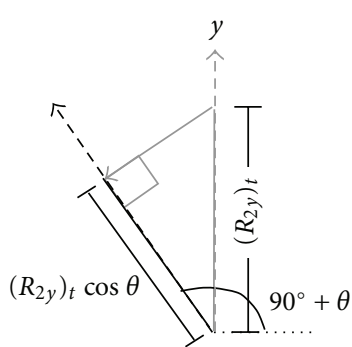

(d)

Figure 3: Schematic response of the example bridge at any time instant $t$ under two orthogonal components of ground motion (plan view); (a) longitudinal response and its projection on $\theta$ axis under $G M_{1}$, (b) transverse response and its projection on $\theta$ axis under $G M_{1}$, (c) longitudinal response and its projection on $(90+\theta)$ axis under $G M_{2}$, and (d) transverse response and its projection on $(90+\theta)$ axis under $G M_{2}$.

to $G M_{1}$ and $G M_{2}$ can be expressed as a combination of $\left(R_{1 \theta}\right)_{t}$ and $\left(R_{2 \theta}\right)_{t}$ :

$$
\left(R_{\theta}\right)_{t}=\sqrt{\left(R_{1 \theta}\right)_{t}^{2}+\left(R_{2 \theta}\right)_{t}^{2}}=\sqrt{\left\{\left(R_{1 x}\right)_{t} \cos \theta+\left(R_{1 y}\right)_{t} \sin \theta\right\}^{2}+\left\{-\left(R_{2 x}\right)_{t} \sin \theta+\left(R_{2 y}\right)_{t} \cos \theta\right\}^{2}} .
$$

Utilizing (3), the maximum resultant response over the entire time history, obtained for one particular value of $\theta$, is

$$
R_{\theta}=\max \left\{\left(R_{\theta}\right)_{t}\right\} .
$$

At $\theta=0^{\circ}, G M_{1}$ and $G M_{2}$ act, respectively, along the longitudinal and transverse directions of the bridge. For this scenario, the maximum response of the bridge at location " $\mathrm{A}$ " over the entire time history is $R_{0}=\max \left\{\sqrt{\left\{\left(R_{1 x}\right)_{t}\right\}^{2}+\left\{\left(R_{2 y}\right)_{t}\right\}^{2}}\right\}$.

In case when only one component of ground motions exists (say, only $G M_{1}$ exists) or a set of two orthogonal components in which one component is negligible (say, $G M_{2}$ is negligible), the maximum resultant response becomes

$$
R_{\theta}=\max \left\{\left(R_{\theta}\right)_{t}\right\}=\max \left\{\left(R_{x}\right)_{t} \cos \theta+\left(R_{y}\right)_{t} \sin \theta\right\},
$$

where $\left(R_{x}\right)_{t}$ and $\left(R_{y}\right)_{t}$ are bridge response, respectively, in the longitudinal and transverse directions at time instant $t$ and location "A" due to a ground motion GM (GM $)$ acting with an angle $\theta$ with the longitudinal axis of the bridge.

2.1. Critical Direction of Ground Motion, $\theta_{\mathrm{cr}}$. The maximum resultant response $R_{\theta}$ is a function of the orientation $(\theta)$ of horizontal ground motion components. Thus, any variation of $\theta$ will result in the variation of $R_{\theta}$. For design purpose, it is important to estimate the maximum earthquake demand resulted from ground motion propagate from all possible directions. The critical direction, $\theta_{\mathrm{cr}}$, for which bridge response will be the maximum can be obtained by $\partial R_{\theta} / \partial \theta=$ 0 . This provides

$$
\theta_{\mathrm{cr}}=\max \left[\frac{1}{2} \tan ^{-1} \frac{2\left\{\left(R_{1 x}\right)_{t}\left(R_{1 y}\right)_{t}-\left(R_{2 x}\right)_{t}\left(R_{2 y}\right)_{t}\right\}}{\left(R_{1 x}\right)_{t}^{2}+\left(R_{2 y}\right)_{t}^{2}-\left(R_{1 y}\right)_{t}^{2}-\left(R_{2 x}\right)_{t}^{2}}\right]
$$




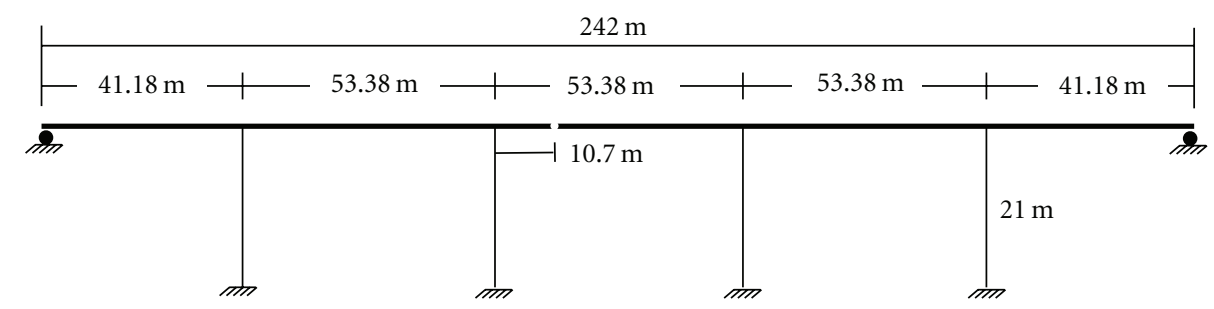

(a)

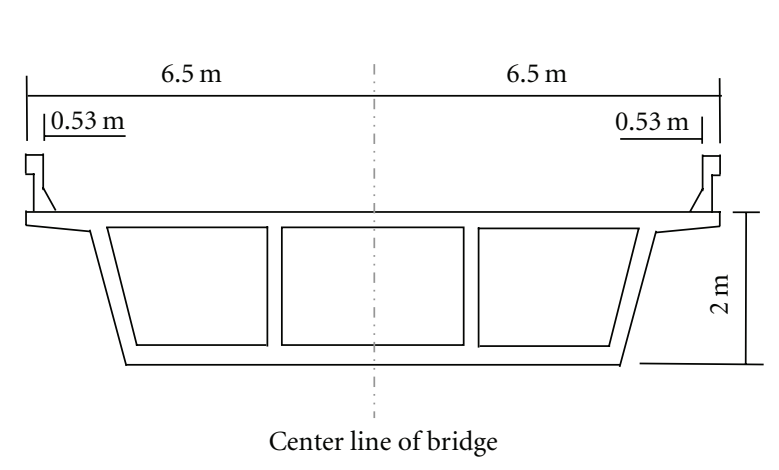

(b)

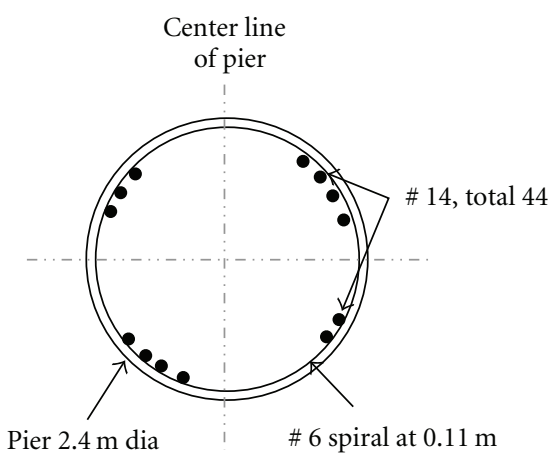

(c)

Figure 4: (a) Bridge model under consideration, (b) cross-section of the bridge girder, and (c) cross-section of pier (not to scale).

when one ground motion component governs, the critical direction becomes (from (5))

$$
\theta_{\mathrm{cr}}=\max \left[\frac{1}{2} \tan ^{-1} \frac{2\left\{\left(R_{x}\right)_{t}\left(R_{y}\right)_{t}\right\}}{\left(R_{x}\right)_{t}^{2}-\left(R_{y}\right)_{t}^{2}}\right] .
$$

The following part of this paper represents a numerical example of a five-span bridge in order to demonstrate the concept presented here. This example provides a probabilistic assessment of bridge response in the form of fragility curves when earthquake ground motions propagate along any horizontal orientation with respect to the longitudinal axis of the bridge. Though this study mainly focuses on one particular highway bridge, the general methodology can be applied to all types of structures. This method uses SRSS rule to capture resultant response and may be used in absence of sophisticated nonlinear analysis. Obviously, rigorous analysis must be performed, particularly for critical structures such as asymmetric buildings, curved or skewed bridges, to accurately estimate nonlinear structural response under earthquake ground motions from various directions.

\section{Numerical Example: Analysis of a Five-Span RC Bridge}

3.1. Example Bridge. A $242 \mathrm{~m}$ long, five-span reinforced concrete $(\mathrm{RC})$ bridge with one expansion joint is considered for the directionality analysis (Figure 4 ). This bridge model was designed following the Caltrans (California Department of Transportation) design guidelines [11]. This bridge is supported on four identical $21 \mathrm{~m}$ high circular RC piers of diameter $2.4 \mathrm{~m}$ that have the same cross-sectional and material properties. Bridge deck is made of 3-cell concrete box girder with section $13 \mathrm{~m}$ wide and $2 \mathrm{~m}$ deep. Young's modulus and mass density of concrete are taken, respectively, as $27.79 \mathrm{GPa}$ and $2.40 \mathrm{t} / \mathrm{m}^{3}$ with $5 \%$ damping ratio at each mode of vibration. For the purpose of the current study, a beam-column model of this bridge is developed and analyzed in time domain using finite element computer code SAP2000 Nonlinear [12]. The bridge deck is integrated with pier bents, so full continuity is considered at girder-pier joints. During longitudinal excitation, bridge superstructure is free to rotate at abutment locations although the translational motion is limited to the initially provided gap between the bridge girder and abutment. During transverse out-ofplane motion, movement of the bridge girder at abutment locations is restrained by wingwalls and concrete shear keys as these are assumed to be rigidly connected with abutments and do not dissipate any energy through yielding [13]. Abutment stiffness values in both directions are determined according to Caltrans' recommendation [14].

During seismic excitation, bending moment generated in bridge piers may lead to formation of plastic hinges at both ends of piers. The complex hysteretic nature of moment-curvature relationship at these plastic hinges is approximated by bilinear behavior as presented in Figure 5 . This nonlinear behavior is modeled by introducing bilinear rotational springs at both ends of bridge piers. Also linear translational springs are introduced at pier bases to account for the resistance offered by the subsurface soil.

At the expansion joint, the example bridge is modeled such that the two ends of an expansion joint can move independently in the longitudinal direction and rotate in longitudinal plane while they have no relative vertical movement. During out-of-plane motion, they are assumed to have 


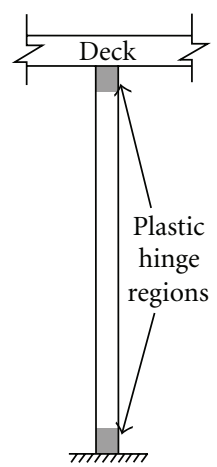

(a)

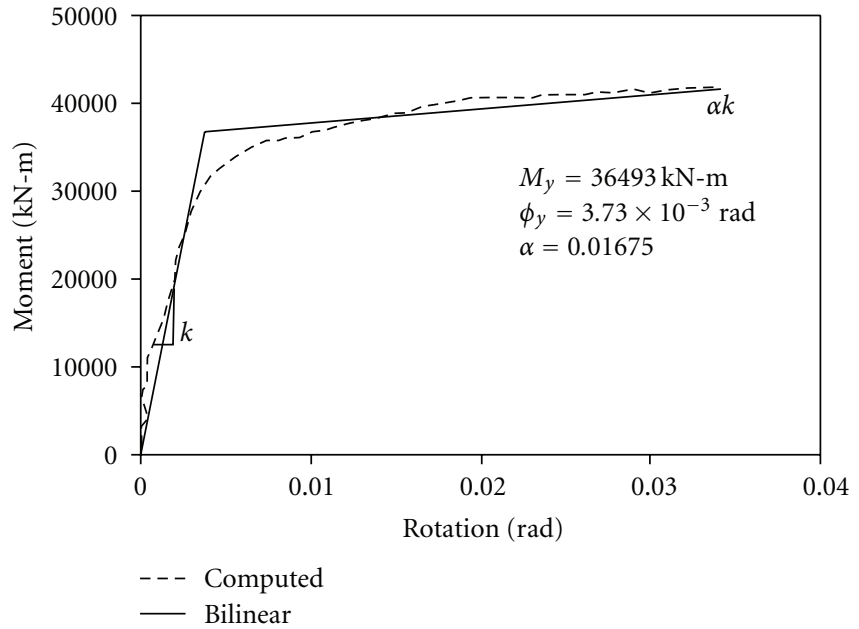

(b)

FIGURE 5: Locations of plastic hinges in the bridge pier and bilinear moment-rotation relationship.

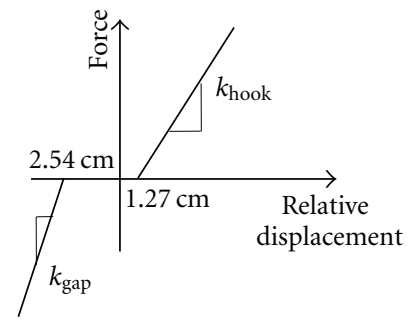

(a)

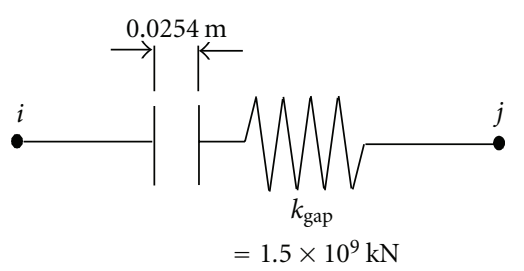

(b)

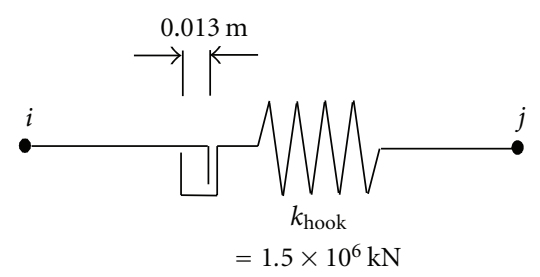

(c)

FIGURE 6: Nonlinear modeling of (a) expansion joint, (b) gap element for pounding at expansion joint, and (c) hook element for restrainer at expansion joint.

a pin connection. The opening and closure of expansion joints during bridge movement are modeled by introducing hook and gap elements, respectively. The hook element represents the effect of restrainer at expansion joint and controls relative displacement (excessive separation) between two adjacent girders. The gap element is provided to take care of pounding effect between two adjacent bridge decks. Figure 6 shows the nonlinear modeling of the expansion joint. As the present study demonstrates the change in bridge damageability due to the change in ground motion orientation, the current nonlinear bridge model serves the purpose adequately.

3.2. Input Ground Motions. Regional seismic hazard is modeled through sixty ground motions which were originally generated by the Federal Emergency Management Agency (FEMA) for Los Angeles, Calif (http://nisee.berkeley.edu/data/strong_motion/sacsteel/ground_motions.html). These ground motions include both recorded and synthetic motions and are categorized into three sets having annual exceedance probabilities of $2 \%, 10 \%$ and $50 \%$ in 50 years. Each set has 10 pairs (20 ground motions); LA01 to LA20 represent moderate motions with annual exceedance probability of $10 \%$, in 50 years, LA21 to LA40 represent strong motions with annual exceedance probability of $2 \%$ in 50 years, and LA41 to LA60 represent weak motions with annual exceedance probability of 50\% in 50 years. In each pair, original horizontal components were resolved into fault-normal and fault-parallel orientations. Table 1 presents the duration, time increments, and PGA values of these motions.

3.3. Nonlinear Time History Analysis. The example bridge is analyzed in time domain under the 60 LA motions in both longitudinal and transverse directions using SAP2000 Nonlinear. This computer code allows the use of Ritz vector in performing dynamic analysis. The first three modes of vibration of the example bridge are shown in Figure 7 in which the 1st mode is in the transverse direction $\left(T_{1}=\right.$ $1.94 \mathrm{sec}$ ) and 2nd and 3rd modes are in the longitudinal direction $\left(T_{2}=1.56 \mathrm{sec}\right.$ and $\left.T_{3}=1.39 \mathrm{sec}\right)$. In the 
TABLE 1: 60 LA ground motions.

\begin{tabular}{|c|c|c|c|c|c|}
\hline Earthquakes & Probability of annual exceedance & ID & PGA $\left(\mathrm{cm} / \mathrm{sec}^{2}\right)$ & Duration (sec) & $\begin{array}{c}\text { Time increment } \\
(\mathrm{sec})\end{array}$ \\
\hline \multirow{2}{*}{$\begin{array}{l}\text { Imperial Valley, 1940, El } \\
\text { Centro }\end{array}$} & \multirow{2}{*}{$10 \%$ in 50 years } & LA01 & 452.03 & 53.48 & 0.02 \\
\hline & & LA02 & 662.88 & 53.48 & 0.02 \\
\hline \multirow{2}{*}{$\begin{array}{l}\text { Imperial Valley, 1979, } \\
\text { Array } 05\end{array}$} & \multirow{2}{*}{$10 \%$ in 50 years } & LA03 & 386.04 & 39.38 & 0.01 \\
\hline & & LA04 & 478.65 & 39.38 & 0.01 \\
\hline \multirow{2}{*}{$\begin{array}{l}\text { Imperial Valley, 1979, } \\
\text { Array } 06\end{array}$} & \multirow{2}{*}{$10 \%$ in 50 years } & LA05 & 295.69 & 39.08 & 0.01 \\
\hline & & LA06 & 230.08 & 39.08 & 0.01 \\
\hline \multirow{2}{*}{ Landers, 1992, Barstow } & \multirow{2}{*}{$10 \%$ in 50 years } & LA07 & 412.98 & 79.98 & 0.02 \\
\hline & & LA08 & 417.49 & 79.98 & 0.02 \\
\hline \multirow{2}{*}{ Landers, 1992, Yermo } & \multirow{2}{*}{$10 \%$ in 50 years } & LA09 & 509.70 & 79.98 & 0.02 \\
\hline & & LA10 & 353.35 & 79.98 & 0.02 \\
\hline \multirow{2}{*}{ Loma Prieta, 1989, Gilroy } & \multirow{2}{*}{$10 \%$ in 50 years } & LA11 & 652.49 & 39.98 & 0.02 \\
\hline & & LA12 & 950.93 & 39.98 & 0.02 \\
\hline \multirow{2}{*}{ Northridge, 1994, Newhall } & \multirow{2}{*}{$10 \%$ in 50 years } & LA13 & 664.93 & 59.98 & 0.02 \\
\hline & & LA14 & 644.49 & 59.98 & 0.02 \\
\hline \multirow{2}{*}{ Northridge, 1994, Rinaldi RS } & \multirow{2}{*}{$10 \%$ in 50 years } & LA15 & 523.30 & 14.945 & 0.005 \\
\hline & & LA16 & 568.58 & 14.945 & 0.005 \\
\hline \multirow{2}{*}{ Northridge, 1994, Sylmar } & \multirow{2}{*}{$10 \%$ in 50 years } & LA17 & 558.43 & 59.98 & 0.02 \\
\hline & & LA18 & 801.44 & 59.98 & 0.02 \\
\hline \multirow{2}{*}{ North Palm Springs, 1986} & \multirow{2}{*}{$10 \%$ in 50 years } & LA19 & 999.43 & 59.98 & 0.02 \\
\hline & & LA20 & 967.61 & 59.98 & 0.02 \\
\hline \multirow{2}{*}{1995 Kobe } & \multirow{2}{*}{$2 \%$ in 50 years } & LA21 & 1258.00 & 59.98 & 0.02 \\
\hline & & LA22 & 902.75 & 59.98 & 0.02 \\
\hline 1989 Loma Prieta & $2 \%$ in 50 years & LA23 & 409.95 & 24.99 & 0.01 \\
\hline & & LA24 & 463.76 & 24.99 & 0.01 \\
\hline 1994 Northridge & $2 \%$ in 50 years & LA25 & 851.62 & 14.945 & 0.005 \\
\hline & & LA26 & 925.29 & 14.945 & 0.005 \\
\hline 1994 Northridge & $2 \%$ in 50 years & LA27 & 908.70 & 59.98 & 0.02 \\
\hline & $2 \%$ ill s0 years & LA28 & 1304.10 & 59.98 & 0.02 \\
\hline 1974 Tabas & $2 \%$ in 50 years & LA29 & 793.45 & 49.98 & 0.02 \\
\hline & & LA30 & 972.58 & 49.98 & 0.02 \\
\hline Elvsian Park (simulated) & $2 \%$ in 50 vears & LA31 & 1271.20 & 29.99 & 0.01 \\
\hline Elystan Park (sminurated) & $2 \%$ ill su years & LA32 & 1163.50 & 29.99 & 0.01 \\
\hline & & LA33 & 767.26 & 29.99 & 0.01 \\
\hline Elysian Park (simulated) & $2 \%$ in 50 years & LA34 & 667.59 & 29.99 & 0.01 \\
\hline Elysian Park (simulated) & $2 \%$ in 50 years & LA35 & 973.16 & 29.99 & 0.01 \\
\hline Elystan Park (simulated) & $2 \%$ in 50 years & LA36 & 1079.30 & 29.99 & 0.01 \\
\hline Palos Verdes (simulated) & $2 \%$ in 50 years & LA37 & 697.84 & 59.98 & 0.02 \\
\hline & & LA38 & 761.31 & 59.98 & 0.02 \\
\hline Palos Verdes (simulated) & $2 \%$ in 50 years & LA39 & 490.58 & 59.98 & 0.02 \\
\hline & & LA40 & 613.28 & 59.98 & 0.02 \\
\hline Covote Lake 1979 & $50 \%$ in 50 vears & LA41 & 578.34 & 39.38 & 0.01 \\
\hline & & LA42 & 326.81 & 39.38 & 0.01 \\
\hline Imperial Valley 1979 & $50 \%$ in 50 vears & LA43 & 140.67 & 39.08 & 0.01 \\
\hline imperial valley, 1919 & $50 \%$ in so years & LA44 & 109.45 & 39.08 & 0.01 \\
\hline & & LA45 & 141.49 & 78.6 & 0.02 \\
\hline Kern, 1952 & $50 \%$ in 50 years & LA46 & 156.02 & 78.6 & 0.02 \\
\hline & & LA47 & 331.22 & 79.98 & 0.02 \\
\hline Landers, 1992 & $50 \%$ in 50 years & LA48 & 301.74 & 79.98 & 0.02 \\
\hline
\end{tabular}


TABle 1: Continued.

\begin{tabular}{|c|c|c|c|c|c|}
\hline Earthquakes & Probability of annual exceedance & ID & PGA $\left(\mathrm{cm} / \mathrm{sec}^{2}\right)$ & Duration (sec) & $\begin{array}{c}\text { Time increment } \\
(\mathrm{sec})\end{array}$ \\
\hline \multirow{2}{*}{ Morgan Hill, 1984} & \multirow{2}{*}{$50 \%$ in 50 years } & LA49 & 312.41 & 59.98 & 0.02 \\
\hline & & LA50 & 535.88 & 59.98 & 0.02 \\
\hline \multirow{2}{*}{$\begin{array}{l}\text { Parkfield, 1966, } \\
\text { Cholame 5W }\end{array}$} & \multirow{2}{*}{$50 \%$ in 50 years } & LA51 & 765.65 & 43.92 & 0.02 \\
\hline & & LA52 & 619.36 & 43.92 & 0.02 \\
\hline \multirow{2}{*}{$\begin{array}{l}\text { Parkfield, 1966, } \\
\text { Cholame 8W }\end{array}$} & \multirow{2}{*}{$50 \%$ in 50 years } & LA53 & 680.01 & 26.14 & 0.02 \\
\hline & & LA54 & 775.05 & 26.14 & 0.02 \\
\hline \multirow{2}{*}{ North Palm Springs, 1986} & \multirow{2}{*}{$50 \%$ in 50 years } & LA55 & 507.58 & 59.98 & 0.02 \\
\hline & & LA56 & 371.66 & 59.98 & 0.02 \\
\hline \multirow{2}{*}{ San Fernando, 1971} & \multirow{2}{*}{$50 \%$ in 50 years } & LA57 & 248.14 & 79.46 & 0.02 \\
\hline & & LA58 & 226.54 & 79.46 & 0.02 \\
\hline \multirow{2}{*}{ Whittier, 1987} & \multirow{2}{*}{$50 \%$ in 50 years } & LA59 & 753.70 & 39.98 & 0.02 \\
\hline & & LA60 & 469.07 & 39.98 & 0.02 \\
\hline
\end{tabular}

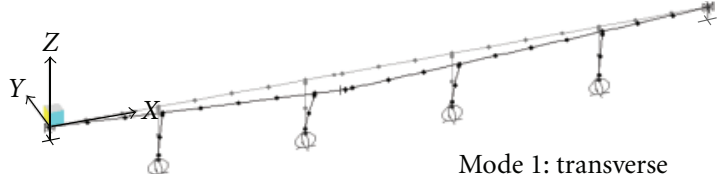

(a)

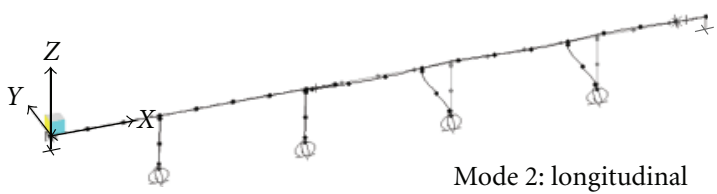

(b)

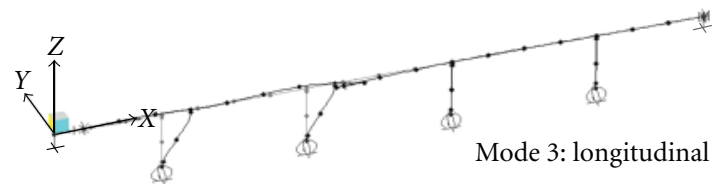

(c)

FIgURE 7: Mode shapes of the example bridge; (a) 1st mode in transverse $(y)$ direction, (b) 2nd mode in longitudinal $(x)$ direction, and (b) 3rd mode in longitudinal $(x)$ direction.

transverse direction, the bridge has very high rotational rigidity at girder level, but the in-span expansion joint acts as a hinge and makes the structure more flexible in this direction than in the longitudinal direction. Two separate sets of 60 nonlinear time history analyses of the bridge are performed considering ground motions are acting along the longitudinal $\left(\theta=0^{\circ}\right)$ and the transverse $\left(\theta=90^{\circ}\right)$ direction of the example bridge. Response is recorded at each time step $(\Delta t)$ of $0.01 \mathrm{sec}$ which is kept unaltered for all ground motions so that the response quantities under two orthogonal components can be combined for the same time instant. Time histories of structural response are computed in terms of (i) the ductility demand at top and bottom of each pier and (ii) the tensile and compressive forces developed

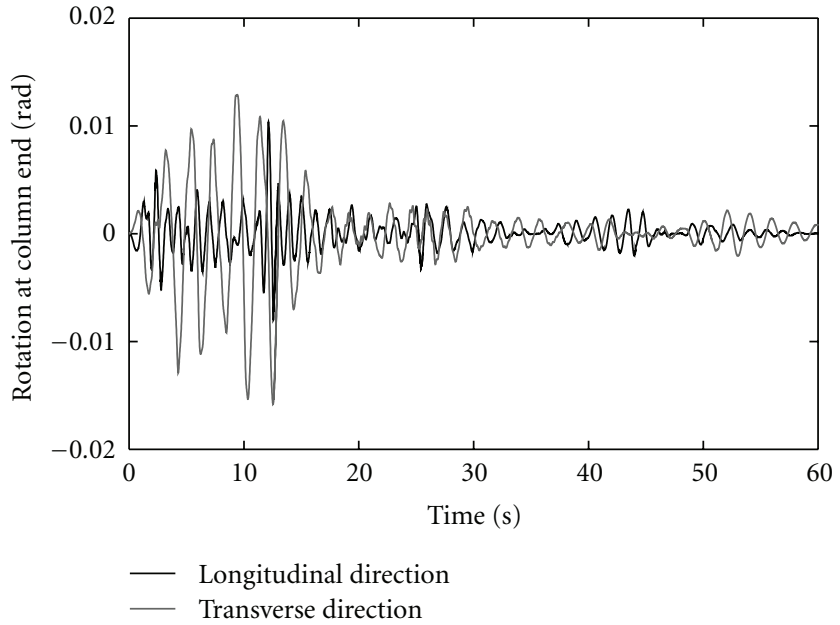

FIGURE 8: Rotation of pier end under one typical ground motion.

at the expansion joint and abutment locations. For the evaluation of seismic performance, possible failure modes and mechanisms are considered which includes formation of plastic hinges at pier ends, unseating and pounding of girders at in-span expansion joints, and abutments of the bridge. All these possibilities are examined independently for each time history. In an earlier study by the authors [15], it was found that failure in the same example bridge was initiated with the formation of significant pier-end hinges. Using this prior knowledge, the current study considers only rotational responses at bridge pier ends to demonstrate the methodology proposed in this paper and to evaluate the directional effect of ground motion. Figure 8 shows the rotational response (in radian) of one of the piers of the example bridge when the ground motion comes along both the longitudinal and transverse directions of the bridge.

3.4. Development of Fragility Curves. Representation of seismic vulnerability of highway bridges in terms of fragility 
curves is a well accepted and appropriate way for a meaningful risk assessment [16-24]. A fragility curve represents structural reliability in the form of a probability distribution function, which is a function of the ground motion intensity. The measures such as peak ground acceleration (PGA), peak ground velocity (PGV), spectral displacement (SD), Spectral Acceleration (SA), and spectral intensity (SI) are often deployed to represent the ground motion intensity (readers may refer to [21] for a summary). Bridge damageability in the form of fragility curves can be incorporated easily in the evaluation of seismic performance of a highway network system. For the purpose of the present study, PGA is considered to represent ground motion intensity. Three damage states namely "Minor," "Moderate," and "Major," are considered which are respectively equivalent to the "Slight," "Moderate," and "Extensive" damage sates as defined in HAZUS [25]. These damage states are quantified in terms of threshold "rotational ductility demand" by calibrating the bridge damage data with the bridge damage observed from past earthquakes [26] and presented in Table 2. The term "rotational ductility demand" can be defined as the ratio of rotation $(\phi)$ of the plastic hinge region of the bridge to the yield rotation $\left(\phi_{y}\right)$.

As stated in Shinozuka et al. [19], fragility curves are developed as two-parameter lognormal distribution function where the parameters (median $c$, and $\log$-standard deviation, $\zeta$ ) are estimated through a maximum likelihood method such that these fragility curves do not intersect each other. Therefore, an equal value of $\zeta$ is needed to satisfy this condition. Under this lognormal assumption, the analytical form of the fragility function $F(\bullet)$ for the state of damage at least $k$ is expressed in (8) where $k$ represents the damage states such as Minor, Moderate, and Major:

$$
F\left(a_{i}, c_{k}, \zeta\right)=\Phi\left[\frac{\ln \left(a_{i} / c_{k}\right)}{\zeta}\right]
$$

Here, $a_{i}$ is the PGA of $i$ th ground motion ( $i=1$ to 60 ), $c_{k}$ is median of the fragility function associated with the damage state of at least $k, \zeta$ is the common log-standard deviation, and $\Phi[\bullet]$ is the standardized normal distribution function. The fragility parameters are computed by maximizing the likelihood function, $L$, which is given by

$$
L\left(c_{1}, c_{2}, c_{3}, \zeta\right)=\prod_{k=0}^{3} \prod_{i=1}^{60}\left[P_{i k}\right]^{x_{i k}},
$$

where $x_{i k}$ is 0 or 1 , depending on whether or not the bridge sustains damage state $k$ under $a_{i}$. $P_{i k}$ is the probability that the example bridge will suffer from a damage state $k$ when subjected to $a_{i}$ and is expressed as

$$
\begin{gathered}
P_{i 0}=1-F\left(a_{i}, c_{1}, \zeta\right), \\
P_{i 1}=F\left(a_{i}, c_{1}, \zeta\right)-F\left(a_{i}, c_{2}, \zeta\right), \\
P_{i 2}=F\left(a_{i}, c_{2}, \zeta\right)-F\left(a_{i}, c_{3}, \zeta\right), \\
P_{i 3}=F\left(a_{i}, c_{3}, \zeta\right) .
\end{gathered}
$$

The fragility parameters are obtained by solving the following equation:

$$
\frac{\partial \ln L\left(c_{1}, c_{2}, c_{3}, \zeta\right)}{\partial c_{k}}=\frac{\partial \ln L\left(c_{1}, c_{2}, c_{3}, \zeta\right)}{\partial \zeta}=0, \quad \forall k .
$$

This process of fragility curve development considering the ground motion directionality can be outlined in steps described next.

(i) Time history traces of rotations at plastic hinge regions of bridge piers are obtained from nonlinear time history analysis of the example bridge under earthquake ground motions. As these ground motions cover a wide range of seismic hazard, analytical result can be used satisfactorily to generate fragility curves.

(ii) Utilizing (1)-(5), the maximum resultant rotations are obtained and converted to rotational ductility demands.

(iii) To check the damage level of the bridge under each earthquake ground motion, the maximum value of ductility demand is compared with threshold ductility demands at different damage states. If the maximum rotational ductility demand is higher than the threshold for a certain damage state, say "Minor," then this represents one simulated data point where at least minor damage is observed at PGA associated with the acceleration time history representing the earthquake.

(iv) From this damage state information of the bridge under 60 ground motions, fragility curves are developed following (8)-(11).

3.5. Case I: Fragility Curves for Two Orthogonal Components of Ground Motion. Utilizing (3) and (4), maximum resultant rotations at all pier ends of the bridge are computed for two orthogonal components of ground motions and for several values of $\theta$. The orthogonal components are considered such that each pair contains two acceleration time histories of the same earthquake. As bridge piers are circular in cross section, the same nonlinear moment-curvature relationship is considered in all directions of pier rotation. Following the procedure indicated earlier, fragility curves are developed for three damage states of the bridge considering $\theta$ as $0^{\circ}, 15^{\circ}$, $30^{\circ}, 45^{\circ}, 60^{\circ}, 75^{\circ}$, and $90^{\circ}$. Estimated fragility parameters are tabulated in Table 3. At any damage level, change in fragility characteristics of the example bridge with $\theta$ is represented by the ratio of median values computed for any value of $\theta$ and $\theta=0^{\circ}$ (i.e., $c_{\theta} / c_{0}$ ) and referred to as the normalized fragility parameters (Table 3 ). Generated fragility curves for different values of $\theta$ at "Moderate" damage level are plotted in Figure 9. Figure 10 shows the variation of $c_{\theta} / c_{0}$ with $\theta$ for three damage levels of the example bridge.

3.6. Case II: Fragility Curves for One Component of Ground Motion. With the aid of (5), maximum resultant rotations at all pier ends of the bridge are computed for different 
TABLE 2: Damage states and threshold rotational ductility demands for the bridge piers.

\begin{tabular}{|c|c|c|}
\hline Damage States & Description of damage states [25] & Threshold rotational ductility demand [26] \\
\hline None & No damage to a bridge & - \\
\hline Slight & $\begin{array}{l}\text { Minor cracking and spalling to abutments, hinges, piers or minor } \\
\text { cracking to the deck }\end{array}$ & 3.39 \\
\hline Moderate & $\begin{array}{l}\text { Any pier experiencing moderate cracking and spalling (pier } \\
\text { structurally still sound), any connection having cracked shear keys } \\
\text { or bent bolts, or moderate settlement of the approach }\end{array}$ & 4.75 \\
\hline Extensive & $\begin{array}{l}\text { Any pier degrading without collapse (pier structurally unsafe), any } \\
\text { connection losing some bearing support, or major settlement of } \\
\text { the approach }\end{array}$ & 8.43 \\
\hline Complete & $\begin{array}{l}\text { Any pier collapsing and connection losing all bearing support, } \\
\text { which may lead to imminent deck collapse }\end{array}$ & - \\
\hline
\end{tabular}

TABLE 3: Fragility parameters of the bridge at different $\theta$ for two orthogonal components of ground motion (case I).

\begin{tabular}{|c|c|c|c|c|c|c|}
\hline \multirow[t]{2}{*}{$\theta$ (degree) } & \multicolumn{3}{|c|}{ Fragility parameters at different damage levels } & \multicolumn{3}{|c|}{ Normalized median values } \\
\hline & $c_{\text {Minor }}(\mathrm{g})$ & $c_{\text {Mod }}(\mathrm{g})$ & $c_{\text {Major }}(\mathrm{g})$ & $\left(c_{\theta} / c_{0}\right)_{\text {Minor }}$ & $\left(c_{\theta} / c_{0}\right)_{\mathrm{Mod}}$ & $\left(c_{\theta} / c_{0}\right)_{\text {Major }}$ \\
\hline 0 & 0.365 & 0.500 & 0.742 & 1.000 & 1.000 & 1.000 \\
\hline 15 & 0.400 & 0.479 & 0.715 & 1.096 & 0.958 & 0.964 \\
\hline 30 & 0.387 & 0.463 & 0.670 & 1.060 & 0.926 & 0.903 \\
\hline 45 & 0.407 & 0.500 & 0.690 & 1.115 & 1.000 & 0.930 \\
\hline 60 & 0.402 & 0.500 & 0.728 & 1.101 & 1.000 & 0.981 \\
\hline 75 & 0.364 & 0.514 & 0.745 & 0.997 & 1.028 & 1.004 \\
\hline 90 & 0.355 & 0.484 & 0.738 & 0.973 & 0.968 & 0.995 \\
\hline
\end{tabular}

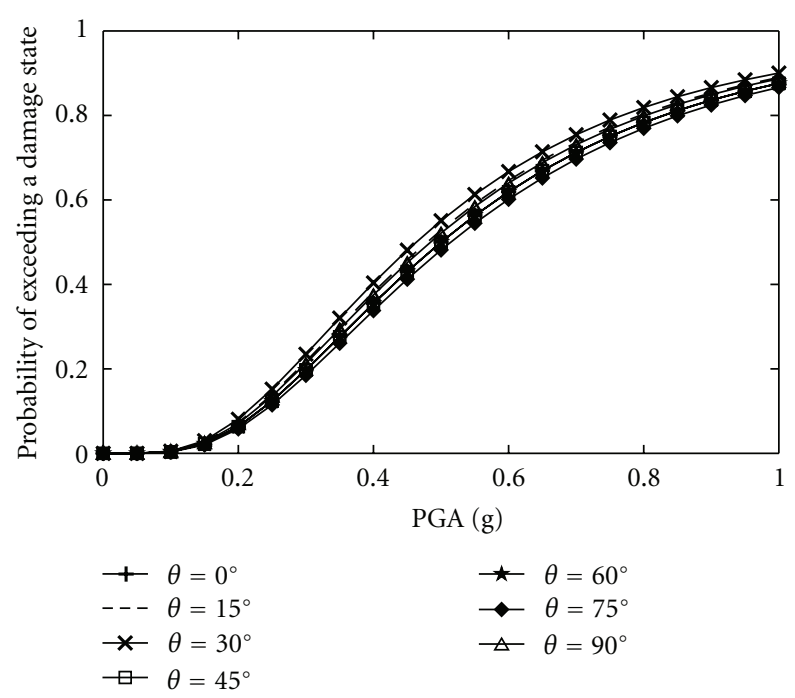

FIGURE 9: Fragility curves of the example bridge at moderate damage state (case I).

orientations $(\theta)$ of one ground motion component. Fragility curves are developed for three damage states of the bridge considering $\theta$ as $0^{\circ}, 15^{\circ}, 30^{\circ}, 45^{\circ}, 60^{\circ}, 75^{\circ}$, and $90^{\circ}$, and estimated fragility parameters are tabulated in Table 4 . This table also represents normalized fragility parameters $\left(c_{\theta} / c_{0}\right)$ obtained for different damage levels. Fragility curves for different values of $\theta$ at "Moderate" damage level are plotted

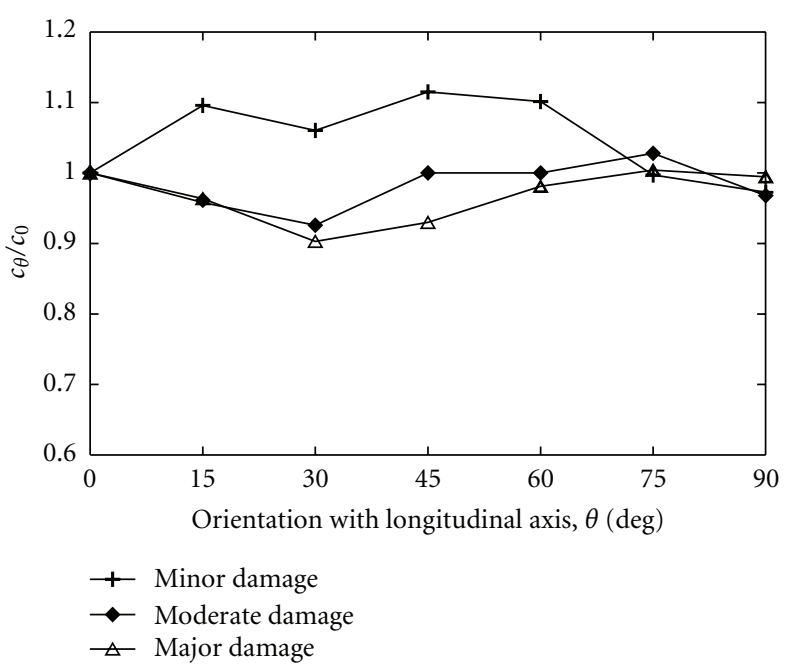

FIgURE 10: Variation of fragility parameter (median) with $\theta$ (case I).

in Figure 11. Figure 12 shows the variation of $c_{\theta} / c_{0}$ with $\theta$ for three damage levels of the example bridge.

\section{Effect of Ground Motion Directionality on Fragility Characteristics}

The effect of ground motion directionality on fragility characteristics of the example bridge is estimated comparing median values $(c)$ of fragility curves obtained for different 
TABLE 4: Fragility parameters of the bridge at different $\theta$ for one component of ground motion (case II).

\begin{tabular}{|c|c|c|c|c|c|c|}
\hline \multirow{2}{*}{$\theta$ (degree) } & \multicolumn{3}{|c|}{ Fragility parameters at different damage levels } & \multicolumn{3}{|c|}{ Normalized median values } \\
\hline & $c_{\text {Minor }}(\mathrm{g})$ & $c_{\text {Mod }}(\mathrm{g})$ & $c_{\text {Major }}(\mathrm{g})$ & $\left(c_{\theta} / c_{0}\right)_{\text {Minor }}$ & $\left(c_{\theta} / c_{0}\right)_{\mathrm{Mod}}$ & $\left(c_{\theta} / c_{0}\right)_{\text {Major }}$ \\
\hline 0 & 0.560 & 0.707 & 1.060 & 1.000 & 1.000 & 1.000 \\
\hline 15 & 0.476 & 0.557 & 0.822 & 0.850 & 0.788 & 0.775 \\
\hline 30 & 0.435 & 0.517 & 0.742 & 0.777 & 0.731 & 0.700 \\
\hline 45 & 0.407 & 0.517 & 0.742 & 0.727 & 0.731 & 0.700 \\
\hline 60 & 0.435 & 0.517 & 0.760 & 0.777 & 0.731 & 0.717 \\
\hline 75 & 0.490 & 0.579 & 0.778 & 0.875 & 0.819 & 0.734 \\
\hline 90 & 0.560 & 0.617 & 0.856 & 1.000 & 0.873 & 0.808 \\
\hline
\end{tabular}

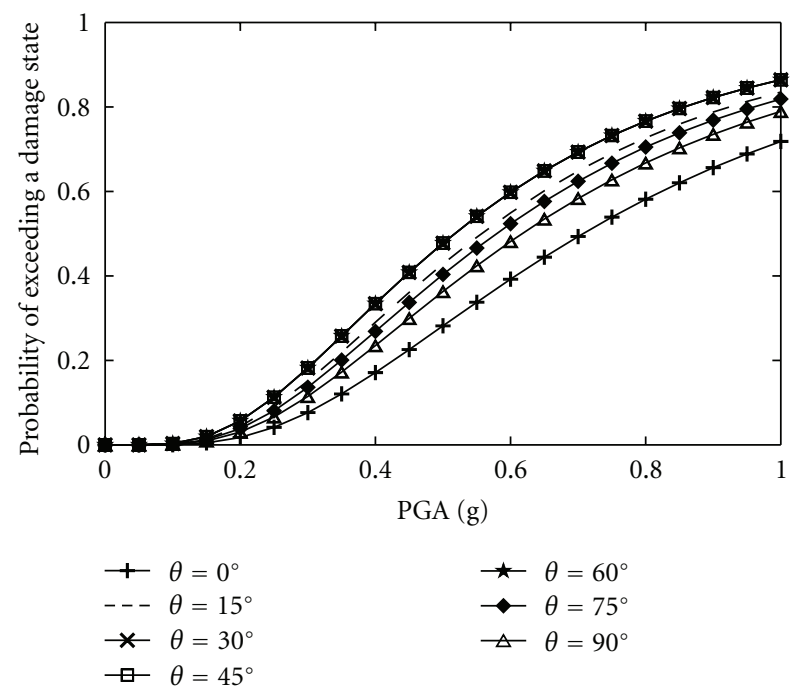

FIGURE 11: Fragility curves of the example bridge at moderate damage state (case II).

$\theta$ values. A fragility curve with a higher median value signifies less probability of failure under certain ground motion intensity (in this study, PGA). Table 3 and Figure 10 show that for a particular state of bridge damage in case I, estimated median fragility parameters $(c)$ for various values of $\theta$ vary within $\pm 11 \%$ from that estimated for $\theta$ $=0^{\circ}$. In case II (Table 4 and Figure 12), median fragility parameters $(c)$ in all states of bridge damage are estimated to be the maximum when ground motions propagate at $\theta=$ $0^{\circ}$ (i.e., the longitudinal axis of the bridge). Therefore for one component of ground motion (i.e., in case II), the example bridge has the least probability of failure for $\theta=0^{\circ}$ in the sense that the bridge is less damageable or less likely to suffer from a damage state than it is for any other value of $\theta$. In this case, the probability of occurring bridge failure at any damage level is maximum at $\theta=45^{\circ}$ for which obtained median fragility parameter $c_{45}$ is 27 to $30 \%$ less than $\mathcal{c}_{0}$. Fragility curves for $\theta=90^{\circ}$ (i.e., along transverse direction) are stronger than those for $\theta=45^{\circ}$ but weaker than those for $\theta=0^{\circ}$. Similar trend is observed in all damage states in case II except for "Minor" damage where the fragility curves in the longitudinal and transverse directions represent the same failure probability. Hence, in summary,

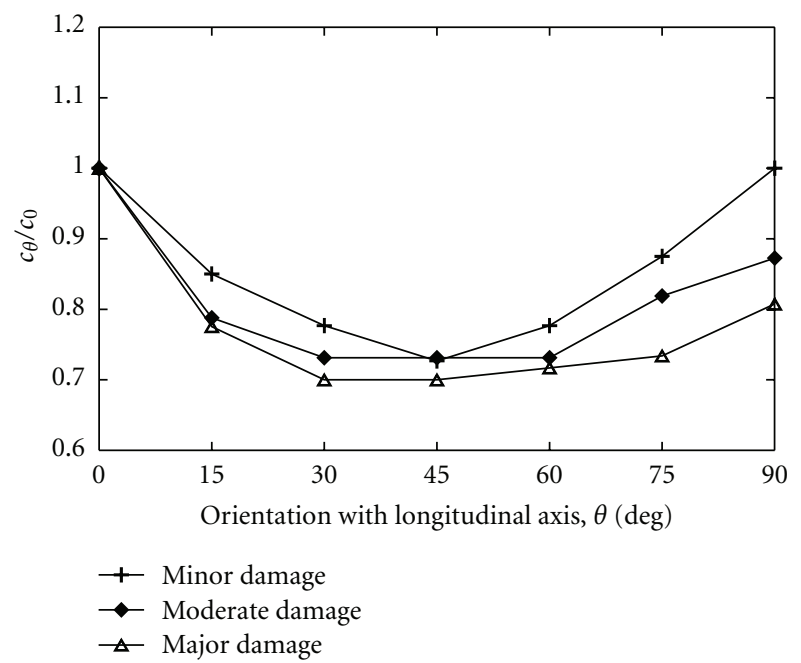

FIgure 12: Variation of fragility parameter (median) with $\theta$ (case II).

(i) in case I, up to $\pm 11 \%$ variation in the median fragility parameter $(c)$ of the example bridge is observed if different values of $\theta$ other than $0^{\circ}$ are considered;

(ii) in case II, the maximum structural response of the example bridge is obtained when ground motions propagate with horizontal orientations $30^{\circ}$ to $60^{\circ}$ with the longitudinal direction of the bridge. The probability of bridge failure is relatively smaller when ground motions act along the longitudinal axis of the bridge. Note that the variation of structural response with the angle of incidence of ground motion is higher in case II than that in case I. This is because the interaction of two orthogonal components results in a reduction of the impact of ground motion directionality in case I (except when $\theta=0^{\circ}$ ).

Obtained result indicates that, in seismic performance analysis, consideration of ground motion acting only along longitudinal and/or transverse directions of the bridge may underestimate the maximum seismic demand. The use of the current method applies on bridges in a highway transportation network consisting of an original composite sample of a large number of bridges having different attributes related to structural characteristics and site soil conditions. Through the analysis of bridge damage data 
from the 1994 Northridge Earthquake involving about 2000 bridges (or consisting of original composite sample of size 2000), Shinozuka et al. $[19,21]$ found three bridge attributes to which the bridge damageability is most sensitive. They are the number of bridge span, skew angle, and site soil condition. For convenience, these attributes are characterized so that the bridge span is either single or multiple, skew angle is $0 \sim 20^{\circ}, 20^{\circ} \sim 60^{\circ}$, or $>60^{\circ}$, and site soil condition is, following the Uniform Building Code (UBC 1993), type A (hard), B (medium), or C (soft). This makes it possible to divide the original composite sample of approximately 2000 bridges into 18 classes each of which consists of a statistically much more homogeneous sample of bridges. Class 1 , for example, consists of bridges with single span, skew angle $0 \sim 20^{\circ}$, and soil type $\mathrm{A}$, and Class 2 with single span, skew angle $0 \sim 20^{\circ}$, and soil type $B$, and so forth. The bridge analyzed in this paper belongs to one of these classes with multiple span, skew angle $0 \sim 20^{\circ}$, and soil type $\mathrm{C}$, and, hence, the quantitative conclusion arrived at in this paper applies to that particular class of bridges only. The general trend of results shown in this study suggests that the effect of ground motion directionality will certainly be a key factor in analyzing the seismic performance of bridges with large skew angles. Nonetheless, separate sets of analysis are required to identify the critical directions of ground motions for such bridges. Fragility curves for these bridges can be estimated using the same procedure as demonstrated in this paper. A comment is made here with respect to the characterization of the attribute in order to develop bridge classes; more fine tuning of the bridge attributes will create a more homogeneous sample at the expense of reducing the sample size accordingly. Hence the fine tuning is made in this paper to achieve a good balance between these two statistical parameters (i.e., homogeneity and sample size).

\section{Conclusions}

For the seismic risk assessment of a highway transportation system, it is important to evaluate the seismic damageability of various bridges with different configurations and site conditions. Bridge damageability information in the form of fragility curve can be easily incorporated in the framework of seismic risk assessment of a highway network. In this relation, this paper addressed the issue of directionality of earthquake ground motion for evaluating the seismic performance of a highway bridge. A simplified practiceoriented analytical method is used considering earthquake ground motions are propagating along arbitrary horizontal directions to the bridge. SAP2000 Nonlinear computer code is used to perform finite element analysis of the bridge. This method is expanded further so that the effect of ground motion(s) orientation can be examined through a parametric study. Result is presented in the form of fragility curves. Analysis is conducted for two independent cases; in the first case, two horizontal orthogonal ground motion components are considered to act simultaneously while in the second case, one component acts. Results from this study showed that ground motion directionality may play an important role in the estimation of maximum seismic demand. For one ground motion component, it is observed that the seismic demand on the example bridge is the maximum when motions propagate with horizontal orientations $30^{\circ}$ to $60^{\circ}$ with the longitudinal direction of the bridge.

\section{References}

[1] S. D. Werner, C. E. Taylor, J. E. Moore, J. S. Walton, and S. Cho, "A risk-based methodology for assessing the seismic performance of highway systems," Tech. Rep. MCEER-000014, Multidisciplinary Center for Earthquake Engineering Research, State University of New York, Buffalo, NY, USA, 2000.

[2] S. Cho, P. Gordon, J. E. Moore, H. W. Richardson, M. Shinozuka, and S. Chang, "Integrating transportation network and regional economic models to estimate the costs of a large urban earthquake," Journal of Regional Science, vol. 41, no. 1, pp. 39-65, 2001.

[3] N. Shiraki, M. Shinozuka, J. E. Moore, S. E. Chang, H. Kameda, and S. Tanaka, "System risk curves: probabilistic performance scenarios for highway networks subject to earthquake damage," Journal of Infrastructure Systems, vol. 13, no. 1, pp. 43-54, 2007.

[4] A. Kiremidjian, J. Moore, Y. Y. Fan, O. Yazlali, N. Basoz, and M. Williams, "Seismic risk assessment of transportation network systems," Journal of Earthquake Engineering, vol. 11, no. 3, pp. 371-382, 2007.

[5] Y. Zhou, S. Banerjee, and M. Shinozuka, "Socio-economic effect of seismic retrofit of bridges for highway transportation networks: a pilot study," Structure and Infrastructure Engineering, vol. 6, no. 1-2, pp. 145-157, 2010.

[6] M. Shinozuka and G. Deodatis, "Simulation of multidimensional Gaussian stochastic fields by spectral representation," Applied Mechanics Reviews, vol. 49, no. 1, pp. 29-53, 1996.

[7] E. L. Wilson and M. R. Button, "Three-dimensional dynamic analysis for multi-component earthquake spectra," Earthquake Engineering and Structural Dynamics, vol. 10, no. 3, pp. 471-476, 1982.

[8] E. L. Wilson, I. Suharwardy, and A. Habibullah, "A clarification of orthogonal effects in a three-dimensional seismic analysis," Earthquake Spectra, vol. 11, no. 4, pp. 659-666, 1995.

[9] O. A. López and R. Torres, "The critical angle of seismic incidence and the maximum structural response," Earthquake Engineering and Structural Dynamics, vol. 26, no. 9, pp. 881894, 1997.

[10] J. J. Hernández and O. A. López, "Response to threecomponent seismic motion of arbitrary direction," Earthquake Engineering and Structural Dynamics, vol. 31, no. 1, pp. 55-77, 2002.

[11] M. Sultan and K. Kawashima, "Comparison of the seismic design of highway bridges in California and in Japan, Recent Selected Publications of Earthquake Engineering Div.," Technical Memorandum of PWRI no. 3276, Public Works Research Institute (PWRI), Japan, 1994.

[12] Computers and Structures, Inc., SAP2000 Nonlinear Users Manual, Version 8, Berkeley, Calif, USA, 2002.

[13] Federal Highway Administration, Seismic design of bridges, Design Example No. 9 FHWA-SA-97-006, 1996.

[14] California Department of Transportation, Seismic Design Criteria, Sacramento, Calif, USA, 2004.

[15] S. Banerjee and M. Shinozuka, "Dynamic progressive failure of bridges," in Proceedings of the ASCE Joint Specialty Conference 
on Probabilistic Mechanics and Structural, Albuquerque, NM, USA, 2004.

[16] H. H. M. Hwang and J.-R. Huo, "Generation of hazardconsistent fragility curves for seismic loss estimation studies," Tech. Rep. NCEER-94-0015, National Center for Earthquake Engineering Research (NCEER), State University of New York, Buffalo, NY, USA, 1994.

[17] S. Fukushima, Y. Kai, and K. Yashiro, "Study on the fragility of system-part 1: structure with brittle elements in its stories," in Proceedings of the 11th World Conference on Earthquake Engineering, Pergamon, Elsevier Science Ltd., 1996, Paper No. 333.

[18] A. Singhal and A. S. Kiremidjian, "Bayesian updating of fragilities with application to RC frames," Journal of Structural Engineering, vol. 124, no. 8, pp. 922-929, 1998.

[19] M. Shinozuka, M. Q. Feng, J. Lee, and T. Naganuma, "Statistical analysis of fragility curves," Journal of Engineering Mechanics, vol. 126, no. 12, pp. 1224-1231, 2000.

[20] K. R. Karim and F. Yamazaki, "Effect of earthquake ground motions on fragility curves of highway bridge piers based on numerical simulation," Earthquake Engineering and Structural Dynamics, vol. 30, no. 12, pp. 1839-1856, 2001.

[21] M. Shinozuka, M. Q. Feng, H. Kim, T. Uzawa, and T. Ueda, "Statistical analysis of fragility curves," Tech. Rep. MCEER03-0002, Multidisciplinary Center for Earthquake Engineering Research (MCEER), The State University of New York, Buffalo, NY, USA, 2003.

[22] E. Choi, R. DesRoches, and B. Nielson, "Seismic fragility of typical bridges in moderate seismic zones," Engineering Structures, vol. 26, no. 2, pp. 187-199, 2004.

[23] S. Banerjee and M. Shinozuka, "Nonlinear static procedure for seismic vulnerability assessment of bridges," Computer-Aided Civil and Infrastructure Engineering, vol. 22, no. 4, pp. 293305, 2007.

[24] S. Banerjee, Statistical empirical and mechanistic fragility analysis of concrete bridges, Ph.D. dissertation, University of California, Irvine, Calif, USA, 2007.

[25] HAZUS, "Earthquake loss estimation methodology," Technical Manual HAZUS99-SR2, National Institute of Building for the Federal Emergency Management Agency, Washington, DC, USA, 1999.

[26] S. Banerjee and M. Shinozuka, "Mechanistic quantification of RC bridge damage states under earthquake through fragility analysis," Probabilistic Engineering Mechanics, vol. 23, no. 1, pp. 12-22, 2008. 

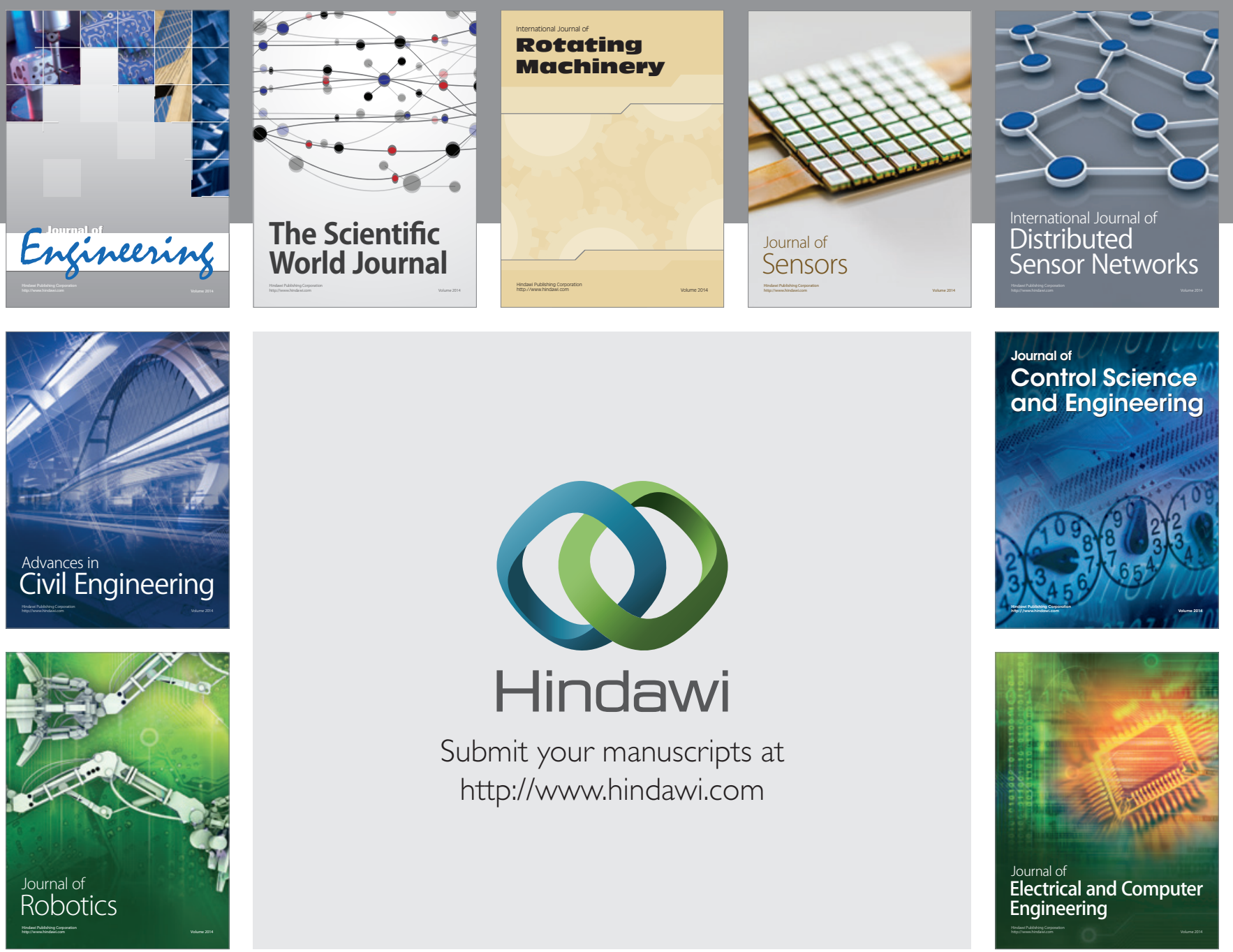

Submit your manuscripts at

http://www.hindawi.com
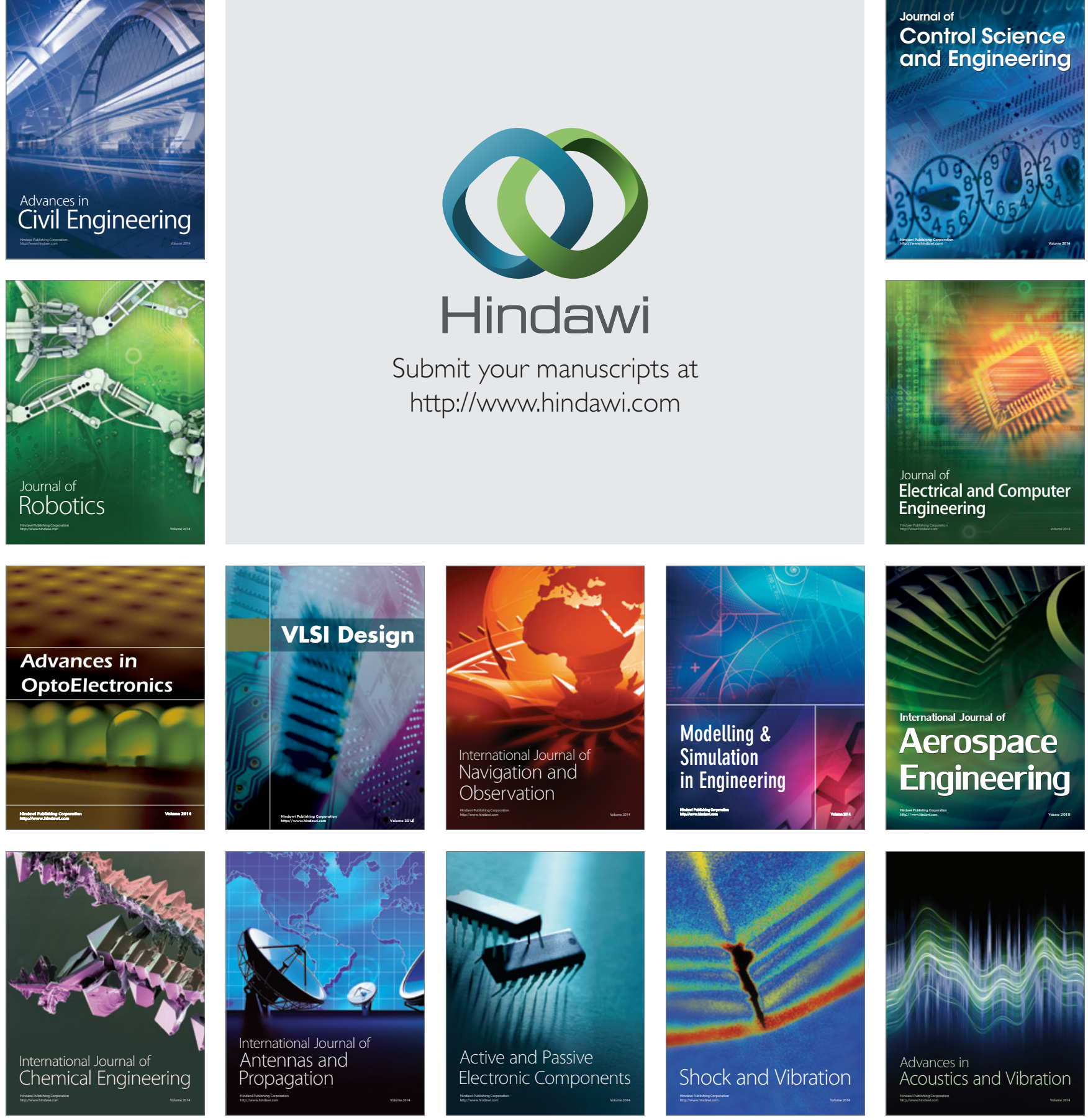